\title{
O que dizem as políticas públicas da agricultura familiar sobre inclusão produtiva? Uma análise sob a abordagem da narrativa governamental
}

\author{
What the public policies of the family agriculture say about productive \\ inclusion? An analysis under of the governmental narrative approach \\ ¿Qué dicen las políticas públicas de la agricultura familiar sobre inclusión \\ productiva? Un análisis bajo el enfoque de la narrativa gubernamental
}

\author{
Diego Neves de Sousa ${ }^{1}$
}

Recebido em 10/06/2019; revisado e aprovado em 19/11/2019; aceito em: 29/11/2019

DOI: http://dx.doi.org/10.20435/inter.v22i2.2606

\begin{abstract}
Resumo: Este artigo propõe reconstruir e analisar a narrativa sobre a temática da inclusão produtiva presente nas políticas públicas da agricultura familiar inseridas no Plano Brasil Sem Miséria (PBSM), sob a perspectiva governamental. Para isso, foi realizada uma pesquisa exploratória, utilizando relatórios governamentais e de outras fontes secundárias que tratam do assunto. O PBSM apresenta uma contextualização que explora a narrativa sobre a pobreza no meio rural brasileiro. Entretanto não existe uma política específica de inclusão produtiva, mas o avanço de um conjunto de políticas complementares no âmbito do PBSM que buscou promover a dinamização socioeconômica dos beneficiários. A tentativa de superar a extrema pobreza do rural demandou, portanto, a ação intersetorial do Estado. Com as alterações recentes no cenário político, constatase a retomada do tema da pobreza e o arrefecimento do tema da inclusão produtiva na agenda política, embora, mais cedo ou mais tarde, essas temáticas precisem ser retomadas em conjunto, para promover a redução da pobreza rural por meio de ações de inclusão produtiva junto aos agricultores familiares.
\end{abstract}

Palavras-chave: Plano Brasil Sem Miséria; pobreza; territórios; desenvolvimento rural.

Abstract: This article proposes to reconstruct and analyze the narrative on the theme of productive inclusion present in family farming public policies inserted in the Brazil Without Misery Plan (PBSM) from the government perspective. For this, an exploratory research was conducted using government reports and other secondary sources that deal with the subject. The PBSM presents a contextualization that explores the narrative about poverty in rural Brazil. However, there is no specific policy of productive inclusion, but the advancement of a set of complementary policies within the PBSM that sought to promote the socioeconomic dynamics of the beneficiaries. The attempt to overcome the extreme poverty of the rural area, therefore, required the intersectoral action of the State. With the recent changes in the political landscape, the issue of poverty is being resumed and the topic of productive inclusion on the political agenda has cooled, although sooner or later these themes will need to be taken up together to promote the reduction of rural poverty through productive inclusion actions with family farmers.

Keywords: Brazil Without Misery Plan; poverty; territories; rural development.

Resumen: Este artículo propone reconstruir y analizar la narrativa sobre el tema de la inclusión productiva presente en las políticas públicas de agricultura familiar insertadas en el Plan Brasil Sin Miseria (PBSM), de acuerdo con la perspectiva del gobierno. Para esto, se realizó una investigación exploratoria, utilizando informes gubernamentales y otras fuentes secundarias que tratan el tema. El PBSM presenta una contextualización que explora la narrativa sobre la pobreza en las zonas rurales de Brasil. Sin embargo, no existe una política específica de inclusión productiva, sino el avance de un conjunto de políticas complementarias dentro del PBSM que buscó promover la dinámica socioeconómica de los beneficiarios. El intento de superar la pobreza extrema del área rural, por lo tanto, requirió la acción intersectorial del Estado. Con los cambios recientes en el panorama político, se reanuda el tema de la pobreza y se enfría el tema de la inclusión productiva en la agenda política, aunque, tarde o temprano, estos temas deban abordarse juntos, para promover la reducción de la pobreza rural a través de acciones de inclusión productiva con agricultores familiares.

Palabras clave: Plan Brasil Sin Miseria; pobreza; territorios; desarrollo rural.

\footnotetext{
${ }^{1}$ Embrapa Pesca e Aquicultura. Palmas, Tocantins, Brasil.
} 


\section{INTRODUÇÃO}

Os estudos relacionados com as políticas públicas iniciaram-se na década de 1950, nos Estados Unidos, numa perspectiva de política pública como ferramenta de análise sobre a ação dos governos. No Brasil, esta área do conhecimento surge na década de 1990, tendo o núcleo de políticas públicas da Universidade Estadual de Campinas (UNICAMP) como pioneiro. Desde então, cresce o interesse e a demanda da sociedade por esta área, na qual se verifica, nos últimos anos, um salto no número de cursos de graduação e de pós-graduação em políticas públicas. Esses cursos buscam discutir e problematizar essa nova área do conhecimento, bem como a formação de recursos humanos para instituições governamentais, de ensino e de pesquisa, para melhor compreensão na tomada de decisão e de implementação de políticas ocorridas no país. Assim, as políticas públicas têm ocupado cada vez mais espaço na sociedade e atuam numa dupla dimensão na construção do conhecimento, seja como instrumento governamental (policy-making process), seja como campo de estudo (policy field).

Na literatura especializada, considera-se que as políticas públicas seguem diferentes etapas, conhecidas como ciclo da política pública, o qual se inicia com a identificação dos problemas, que são contextualizados em seus diversos segmentos da sociedade e levados a cabo junto ao governo, por meio de demandas na busca por soluções. Se ganhar espaço na agenda setting, as instituições formulam alternativas e selecionam soluções aplicadas às políticas públicas e, então, essas são implementadas, avaliadas e revisadas (SABATIER, 2007). Nesse intento, podese definir política pública como o campo do conhecimento que busca "colocar o governo em ação", analisando este tipo de ação e, se necessário, recomendando mudanças no decorrer das ações propostas (SOUZA, 2006).

A análise de políticas públicas pode ser considerada uma forma de ponderar as ações desenvolvidas ou não desenvolvidas pelo governo, a fim de agenciar determinado problema, numa específica realidade social. Essa análise vai além da observação e apreciação dos resultados de tal política pública, preocupando-se com o processo de construção, tendo o foco na formulação da agenda e destacando aspectos como: interesses dos atores colocados na arena e suas respectivas interações, arquitetura do poder, tomada de decisões, conflitos, negociações e acordos políticos (SERAFIM; DIAS, 2012).

Para entender as contribuições e limitações das políticas públicas e sua adequada aplicabilidade, faz-se necessário ter em atenção os diferentes modelos teóricos que possibilitam a compreensão da realidade, as ideias, as crenças e as interpretações de mundo na construção das políticas públicas; os atores e seus interesses na intervenção do Estado; bem como as instituições, suas oportunidades e resistências nos processos. Existe uma gama de modelos que permitem analisar as políticas públicas sob diferentes perspectivas, tais como o ciclo de política pública (policy cycle), lata de lixo (garbage can), coalizões de interesse (advocacy coalition), múltiplos fluxos e equilíbrio pontuado, abordagem dos referenciais, fóruns, arenas sociais, comunidades epistêmicas, narrativas, discursos, escolhas racionais, neoinstitucionalistas, redes, entre outras. Dessas, escolheu-se para balizar este estudo a noção de narrativa (ROE, 1994; RADAELLI, 2006), que está inserida no contexto da abordagem² cognitiva de análise de políticas públicas.

\footnotetext{
${ }^{2}$ Esta abordagem é focada em analisar o papel das ideias e das argumentações na formulação das políticas públicas e o protagonismo dos atores sociais na produção de representações sobre os problemas sociais e de respostas para eles (GRISA, 2012; LUKIC; TOMAZINI, 2013; FRANÇA, 2016).
} 
Neste contexto, este artigo propõe reconstruir e analisar a narrativa sobre a temática da inclusão produtiva presente nas políticas públicas da agricultura familiar inseridas no Plano Brasil Sem Miséria (PBSM), sob a perspectiva governamental. A importância em analisar as políticas públicas direcionadas à agricultura familiar é devido ao seu reconhecimento como categoria sociopolítica e ao novo contexto da trajetória ${ }^{3}$ das políticas direcionadas aos diferentes segmentos específicos da agricultura familiar (extrativistas, quilombolas, assentados, pescadores, indígenas etc.) no país. A partir disso, segmentos mais empobrecidos e com certas privações da agricultura familiar tiveram suporte em políticas atinentes à inclusão produtiva, tal como ocorreu no PBSM, que é o objeto empírico deste estudo, com o propósito de tornar residual o percentual da população rural que vive abaixo da linha da pobreza, com o foco no fortalecimento da capacidade produtiva dos agricultores para o autoconsumo e, sobretudo, para o mercado obtido por meio de apoio financeiro, acesso a insumos agrícolas e do serviço de extensão rural.

Em contrapartida, verifica-se a emergência da temática inclusão 4 produtiva nos estudos rurais e na agenda política. No entanto o termo ainda não é consenso entre os policy makers e os mediadores que atuam com este tipo de política pública. O tema foi primeiramente evidenciado por meio das políticas territoriais, como o Programa Nacional de Desenvolvimento Sustentável de Territórios Rurais (Pronat) e o Programa Territórios da Cidadania (PTC), embora esses Programas provavelmente tenham sido aqueles que mais fortemente destacaram a inclusão produtiva como estratégia voltada para os agricultores pobres (CAVALCANTI; WANDERLEY; NIEDERLE, 2014). Por sua vez, no estudo conduzido por Sousa (2019a), constatou-se ainda que os mediadores sociais não consideram o PBSM nem as políticas territoriais como promotores da inclusão produtiva. A justificativa é de que essas políticas saíram da agenda governamental e não são mais consideradas referência para este público.

O artigo está organizado em quatro seções, além desta introdução, que se destacou pela apresentação sobre a emergência dos estudos de políticas públicas e sua relação com a temática da inclusão produtiva. Na seguinte seção, são apresentados os procedimentos metodológicos deste trabalho. Na terceira seção, faz-se uma discussão à luz da narrativa como ferramenta para análise em políticas públicas. Na quarta, discutem-se os resultados obtidos nas narrativas governamentais, acerca das políticas públicas da agricultura familiar e sua imbricação com a inclusão produtiva no contexto do PBSM. Por último, as considerações finais sobre os principais elementos discutidos neste artigo.

\section{METODOLOGIA}

Este trabalho é caracterizado como exploratório de cunho qualitativo, no qual se adotaram dados secundários. A análise de dados secundários é uma técnica que possibilita ampliar a

\footnotetext{
3 “Iniciando uma nova trajetória para a categoria social, a Constituição de 1988 incitou novos espaços de participação social e reconheceu direitos; a criação do Programa Nacional de Fortalecimento da Agricultura (Pronaf) em 1995 desencadeou a emergência de outras políticas diferenciadas de desenvolvimento rural; a criação do Ministério do Desenvolvimento Agrário (MDA) em 1999, e da Secretaria da Agricultura Familiar (SAF) no interior deste em 2001, institucionalizaram a dualidade da estrutura agrária e fundiária no País; e em 2006 foi regulamentada a Lei da Agricultura Familiar que reconheceu a categoria social, definiu sua estrutura conceitual e passou a balizar as políticas públicas para este grupo social" (GRISA; SCHNEIDER, 2014, p. 126-7).

${ }^{4}$ Sobre a discussão em torno do que se entende por inclusão produtiva, ver os estudos de Sousa e Niederle (2018) e Sousa (2019a; 2019b).
} 
compreensão dos objetos empíricos que necessitam de contextualização, de acordo com suas especificidades, pois cada documento tem sua identidade própria e entre si podem proporcionar diálogo (LÜDKE; ANDRÉ, 1986).

Em um primeiro momento, recorreu-se às narrativas utilizadas por agentes do governo para retratar sobre a formulação e avaliação do PBSM, ou seja, para analisar a situação antes e depois da implementação desta política. Para isso, utilizou-se de relatórios institucionais disponibilizados pelo Ministério do Desenvolvimento Social e do Ministério do Desenvolvimento Agrário sobre o referido Programa.

Pobreza rural e inclusão produtiva foram as categorias analíticas ${ }^{5}$ adotadas por este estudo. Para o tratamento dos dados, empregou-se a análise de conteúdo do tipo temática, por ser

[...] um conjunto de técnicas de análise de comunicação visando a obter, por procedimentos sistemáticos e objetivos de descrição do conteúdo das mensagens, indicadores (quantitativos ou não) que permitam a inferência de conhecimentos relativos às condições de produção/ recepção destas mensagens. (BARDIN, 2011, p. 42).

A fim de complementar essas informações, em um segundo momento foram analisadas as legislações das políticas públicas imersas no PBSM, com vistas a identificar a relação que existe com a temática inclusão produtiva.

\section{A NARRATIVA COMO FERRAMENTA DE ANÁLISE EM POLÍTICAS PÚBLICAS}

A narrativa é um modelo teórico de análise em políticas públicas (policy analysis), que visa melhor compreender as mudanças ocorridas em uma determinada política por meio de histórias, narrativas e discursos que dão significado à realidade investigada. É um tipo de discurso caracterizado pela temporalidade, pelo encadeamento de eventos críticos e pela presença de uma trama principal cerceada de atores sociais que se interagem (ALVES; BLIKSTEIN, 2006).

A importância da narrativa para a análise de políticas públicas é justificada no fato de que "Stories commonly used in describing and analyzing policy issues are a force in themselves, and must be considered explicitly in assessing policy options" (ROE, 1994, p. 2).

Para Radaelli (2006) e Grisa (2012), a narrativa pode ser compreendida a partir de diferentes argumentações e percepções, consideradas "verdadeiras" de acordo com a referência da fonte de dados coletada, expressa numa determinada história casual que abrange o início, o meio e o fim, e, às vezes, gera uma conclusão moralizadora. Dessa forma, a narrativa enfatiza a sequência temporal ${ }^{6}$ dos acontecimentos, no qual o presente está enraizado numa série de eventos que começam no passado e terminam no futuro.

O enfoque narrativo sugere que, em volta de uma determinada política pública, tecem-se relatos de diferentes atores sociais, que evidenciam a polarização dos assuntos públicos numa coalizão de interesses, assim como explicado por Blandón (2014, p. 440).

Esto no solo explica la dinámica del proceso de la política pública, al demostrar la presencia de narrativas múltiples y contradictorias, sino que además, otorga igual peso a las narrativas de los actores, de forma que distintas versiones de un mismo asunto sean consideradas

\footnotetext{
${ }^{5}$ Os conceitos mais importantes de uma teoria perpassam pelas categorias analíticas que retêm as relações sociais fundamentais e podem ser balizadas para o conhecimento dos aspectos gerais do objeto de estudo (MINAYO, 2015).

${ }^{6}$ A ordem temporal e a coerência das sequências dos fatos da história narrada é mais importante que a exatidão ou a falsidade dos elementos que referenciam tal argumentação (RADAELLI, 2006).
} 
en el proceso de formulación de las políticas, particularmente en los asuntos complejos e inciertos y que suscitan polarización.

Nesse mesmo intento, conforme salienta Roe (1994, p. 3), as narrativas são tidas como "[...] those stories - scenarios and arguments - that are taken by one or more parties in the controversy as underwriting and stabilizing the assumptions for policymaking in the face of the issue's uncertainty, complexity or polarization".

$\mathrm{Na}$ análise narrativa, trata-se de dar sentido à forma como um relato é comunicado, fornecendo normas para o comportamento, dramatizando o contexto ou provocando emoções no interior de um referencial. Desse modo, verifica-se que o poder de uma narrativa está na sua lógica, na coerência de ideias e de emoção, em que a tensão de um drama emotivo e os elementos constitutivos perpassam a escolha de um futuro (RADAELLI, 2006).

Como explica Radaelli (2000, p. 256), “[...] os atores estão imersos em uma estrutura cognitiva (um paradigma, uma narrativa dominante, um discurso ou um referencial), mas as matrizes cognitivas somente operam através do comportamento dos atores". Considera-se, então, a narrativa como sendo um recurso cognitivo, com enfoque no poder da comunicação, porém é delimitada a partir da ligação entre agência e estrutura em que a ação é circunscrita (RADAELLI, 2006).

As relações de poder enraizadas na noção do enfoque narrativo são tratadas por Grisa (2012, p. 52), ao explicar que "Quando uma narrativa torna-se hegemônica e institucionaliza suas ideias, ela altera as relações de força concedendo mais poder ao grupo de atores portador da nova narrativa, enquanto a influência dos antecessores está em declínio". Radaelli (2000) complementa que a narrativa hegemônica age como um prisma conceitual que obscurece e rejeita as possibilidades de ações alternativas; por outro lado, é de significante importância considerar também a narrativa pelo que ela não relata (ou que é silenciada).

A análise de narrativas procura explicitar as relações de poder, envolvendo uma narrativa dominante e outra marginal, além de diferentes variáveis para melhor compreender o impacto de uma narrativa na mudança estrutural de uma determinada política pública (GRISA, 2012).

A função adequada das narrativas de políticas públicas é, sobretudo, a busca por garantir, certificar e estabilizar hipóteses indispensáveis para a tomada de decisão em relação ao que é incerto e complexo nos problemas sociais. Verifica-se, ainda, que não são propriamente as ideias que alteram as políticas públicas, mas o modo como é configurada a percepção dos atores sociais na arena de disputas, com capacidade de ação institucional, competências, recursos e poder de veto (RADAELLI, 2006). É por isso que as ideias desenhadas pelas narrativas são importantes para a melhor compreensão dos fatos nas tomadas de decisão pelos governos, na formulação, elaboração e análise de políticas públicas.

Portanto pode-se compreender que, nos estudos sobre a narrativa, salienta-se a importância de como as mudanças ocorridas nas políticas públicas são interpretadas e como auxiliam na "[...] construção de um contexto favorável às mudanças políticas ao alterarem as percepções dos atores em relação aos problemas públicos e as possíveis soluções, influenciando suas preferências" (GRISA; SCHNEIDER, 2014, p. 55). No entanto outros autores realçam que esses são alguns dos fatores variáveis que podem explicar possíveis mudanças ou influências nas narrativas de políticas públicas, o que pode dar margem para que o enfoque narrativo seja percebido de forma unilateral (ROE, 1994; RADAELLI, 2006; BLANDÓN, 2014). 


\section{A ANÁLISE DAS NARRATIVAS NA CONSTRUÇÃO DE POLÍTICAS PÚBLICAS DE INCLUSÃO PRODUTIVA DA AGRICULTURA FAMILIAR}

Esta seção tem como proposta descrever a narrativa acerca das políticas públicas da agricultura familiar e sua imbricação com o tema da inclusão produtiva no contexto do PBSM, sob a ótica governamental. Essa análise foi realizada a partir de relatórios oriundos do PBSM e de documentos acadêmicos e normativos que tratam deste assunto. Diante disso, pretende-se responder às seguintes perguntas: qual é a narrativa utilizada pelo governo para sustentar o Plano Brasil Sem Miséria? Qual é a argumentação que o governo manteve para a inserção da temática inclusão produtiva? E, por último, qual o argumento para inserção de políticas específicas para a promoção da inclusão produtiva rural neste Programa?

Lançado no ano de 2011, o PBSM teve a finalidade de promover a inclusão social e produtiva da população que estava inserida na faixa de extrema pobreza, sendo que a proposta do governo federal era de tornar residual o percentual dos que viviam abaixo da linha da pobreza. A ideia foi reunir diversas políticas públicas para a promoção do desenvolvimento rural no país, a partir de três níveis estratégicos (Ver Figura 1): garantia de renda, acesso aos serviços públicos e promover ações de inclusão produtiva no meio rural e urbano (BRASIL, 2015a), sendo que este artigo pretende dar ênfase analítica às estratégias de inclusão produtiva no meio rural.

Figura 1 - Eixos estratégicos do Plano Brasil Sem Miséria

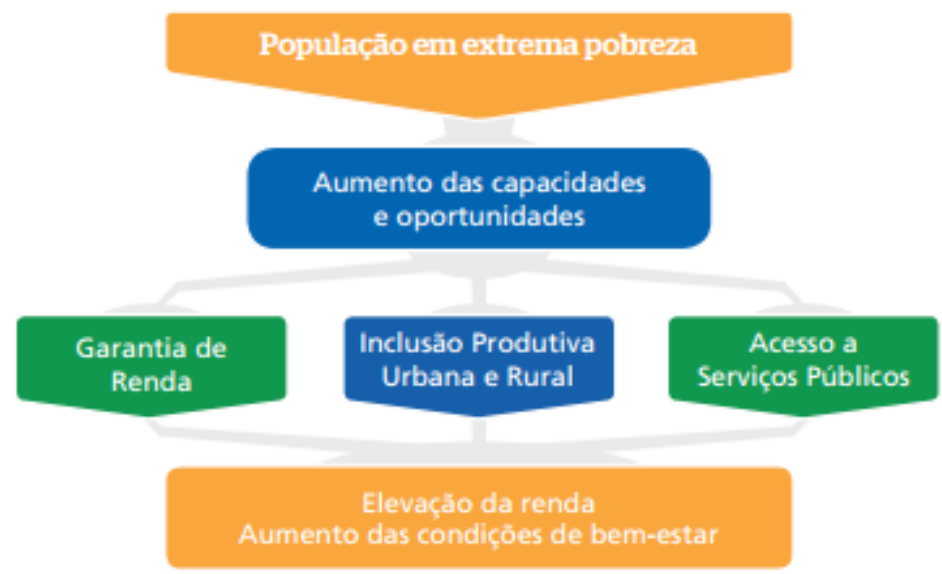

Fonte: Brasil (2013c).

O problema identificado para a construção da proposta do PBSM foi embasado a partir dos resultados identificados no diagnóstico proveniente do IBGE (2011), que identificou 16,2 milhões de brasileiros que se encontravam na linha da pobreza com rendar familiar menor que $\mathrm{R} \$$ 70,00/ mensais (BRASIL, 2012c). Com essa estatística, o governo oficializou que o público prioritário do PBSM fossem os brasileiros com o perfil socioeconômico enquadrado prioritariamente na faixa de extrema pobreza.

Assim sendo, percebe-se que os think tanks que influenciaram a construção e a implementação desta política, por meio de assessoria e subsídio às informações geradas, estavam vinculados à área do conhecimento da estatística e da socioeconomia, devido ao argumento utilizado para convencer os políticos a lançarem o PBSM. 
Este fato pode ser mais bem entendido, de acordo com Brasil (2015a), ao se analisar os dados do Censo Demográfico de 2010, o qual aponta que 25,5\% dos brasileiros residentes no meio rural estão numa situação de extrema pobreza, contra 5,4\% da população urbana. Outros dados significativos são de que $20 \%$ da população rural é analfabeta, em relação a 7,7\% nas cidades. Isto é uma das variáveis que criam distorção de desigualdades entre o rural e o urbano no acesso aos serviços de infraestrutura básica. Essa realidade representa um desafio de viver no meio rural brasileiro, a ponto de apresentar dificuldades em manter a sucessão familiar (numa perspectiva de reprodução social) e em manter a unidade produtiva econômica em exercício. "Daí a importância das ações de inclusão produtiva rural, que ajudam as famílias em extrema pobreza a produzir mais e melhor, e a comercializar seus produtos" (BRASIL, 2012c, p. 7).

Em outra fonte de informação, foi verificado que, dos 5,4 milhões de agricultores familiares que possuem a Declaração de Aptidão ao PRONAF (DAP), aproximadamente 65\% estão cadastrados no Cadastro Único para Programas Sociais (Cadúnico ${ }^{7}$ ) e recebem os benefícios do Programa Bolsa Família, por estarem enquadrados na faixa salarial per capita. No caso deste recorte amostral, verificou-se que $78 \%$ deste público têm renda mensal de até $R \$ 154,00$, o que é considerado população em extrema pobreza (BRASIL, 2015c). Esses dados vão ao encontro do que foi divulgado no Censo realizado em 2010.

Para melhor entendimento dos extratos que se declararam inseridos nos diversos segmentos da agricultura familiar e, concomitantemente, recebem o recurso do Programa Bolsa Família, o Quadro 1 ilustra os beneficiários desta política pública social, tendo como referência o ano de 2012. Destaca-se que os principais beneficiários em nível quantitativo foram os agricultores familiares $(34,3 \%)$, seguidos pelos indígenas $(29,8 \%)$ e quilombolas $(20,2 \%)$, respectivamente.

Quadro 1 - Mapeamento dos grupos que receberam o Bolsa Família no ano de 2012

\begin{tabular}{|l|c|}
\hline Grupos & Quantitativo \\
\hline Indígenas & 82.924 \\
\hline Quilombolas & 56.110 \\
\hline Em situação de rua & 3.320 \\
\hline Ciganos & 549 \\
\hline Extrativistas & 2.406 \\
\hline Pescadores artesanais & 11.190 \\
\hline Comunidade de terreiro & 117 \\
\hline Ribeirinhos & 3.156 \\
\hline Agricultores familiares & 95.442 \\
\hline Assentados da Reforma Agrária & 11.917 \\
\hline Programa Nacional de Crédito Fundiário & 449 \\
\hline Acampados & 1.081 \\
\hline Atingidos por empreendimento de infraestrutura & 375 \\
\hline Presos por Sistema Carcerário & 1.142 \\
\hline Catadores de material reciclável & 7.501 \\
\hline Total & 277.679 \\
\hline
\end{tabular}

Fonte: Brasil (2012c).

\footnotetext{
${ }^{7}$ Este instrumento governamental cadastra famílias com renda mensal de até meio salário mínimo por pessoa para o acesso às políticas de transferência de renda.
} 
É sobre esse discurso, pautado por dados estatísticos, que surge a narrativa para a implementação do PBSM, visto que a inserção da temática pobreza na agenda setting nacional tem se destacado desde a década de 1990, com políticas que enfatizam a ideia de enfrentamento da pobreza, como foi com o pioneiro Programa Fome Zero e as políticas territoriais. De acordo com Mattei (2013), a maioria dos estudos e pesquisas tem como ponto de partida a análise da renda monetária per capita das famílias, porque este tipo de variável está mais disponível do que os demais e, de certa forma, é atualizado com frequência.

Desse modo, esse diagnóstico ${ }^{8}$ constituiu as ideias que motivaram a criação do PBSM, a fim de fortalecer os agricultores familiares na tentativa de reduzir as desigualdades socioeconômicas e superar a pobreza no campo. Para comprovar tal argumento, seguem abaixo algumas narrativas identificadas de representantes do governo sobre o PBSM e o que representa este Programa no meio rural.

A Ministra Tereza Campello destacou que a extrema pobreza é um fenômeno multidimensional que vai muito além da transferência de renda, por isso o Plano Brasil Sem Miséria é composto por um conjunto de programas e ações que transcendem a questão da renda. Com o Brasil Sem Miséria, a partir de março de 2013 não há mais famílias do Programa Bolsa Família abaixo da linha da extrema pobreza (70 reais por pessoa). (BRASIL, 2013a, p. 15).

"O programa é o principal símbolo na busca da igualdade", destacou o ministro-chefe da Secretaria de Assuntos Estratégicos da Presidência da República, Marcelo Neri. "Sem ele, a pobreza subiria $36 \%$ no mesmo período e poderia ser maior por causa do efeito multiplicador. (SERGIPE, 2014, s. p.).

A ministra do Desenvolvimento Social lembra que, embora apenas 15\% dos brasileiros estejam na zona rural, metade da população em extrema pobreza na época do lançamento do Brasil Sem Miséria vivia no campo. "Por isso, a política do governo para a superação da miséria requer uma estratégia específica para lidar com a pobreza no meio rural, ajudando as famílias a produzir mais e melhor e a comercializar seus produtos", ressalta. (SERGIPE, 2014, s. p.).

Além disso, a dramatização em torno de superar a extrema pobreza até o ano de 2014 foi a janela de oportunidade para a sensibilização do primeiro governo de Dilma Rousseff em continuar com ações de superação da pobreza, algo já institucionalizado no governo anterior e que foi materializado por meio do lançamento do PBSM.

Em outras palavras, verificou-se que foi construído um drama que ajudou a convercer as pessoas de que era a "melhor" política pública e, caso ela não fosse implementada, a pobreza no Brasil se elevaria. Como forma de inserir a sociedade civil como partícipe no processo, antes do lançamento, o governo discutiu ${ }^{9}$ a proposta com diversos segmentos da sociedade civil, para legitimar o PBSM e ter apoio político necessário para expandir e consolidar esta política (BRASIL, 2011a). O que se percebe é que a participação social se tornou importante instrumento de gestão pública, dando visibilidade aos representantes dos mais pobres (e/ou excluídos) por meio de eventos denominados de "Diálogos". Isto demonstra

[...] que os Diálogos tenham ocorrido muito próximos ao anúncio oficial do Plano, grande

\footnotetext{
${ }^{8}$ Foram também diagnosticados no meio rural os problemas de emissão de DAP, dificuldades de acesso ao crédito e à comercialização, além da produção escassa de alimentos nas famílias de agricultores extremamente pobres (BRASIL, 2012c).

${ }^{9}$ Nesta ocasião, deu origem ao documento "Devolutiva". Este relata as providências e ações adotadas pelo governo com o intuito de ser divulgado para a sociedade civil (BRASIL, 2012a).
} 
parte das contribuições será incorporada ao longo de sua implementação, uma que trata-se de estratégia em processo contínuo de aperfeiçoamento. E mais: os momentos de interlocução com a sociedade apenas se iniciaram com essa primeira rodada de conversas. A proposta é continuar e aprofundar a participação social no Brasil Sem Miséria. (BRASIL, 2011a, p. 2).

Com uma visão multidimensional de integração e articulação de políticas públicas, programas e ações, e com o apoio do diagnóstico que constatou o perfil da população dos extremamente pobres, o PBSM apresentou uma narrativa que contextualizou a exploração da pobreza no meio rural, no sentido de buscar extingui-la do cenário nacional. A ideia principal amparou-se no fato de que as políticas fossem interministeriais/intersetoriais para abranger maior público, e que as próprias políticas complementassem umas às outras, conforme se verifica na Figura 2, ao retratar o organograma da rede de atores sociais que interagiu no PBSM rural, por meio do Programa Fomento, juntamente do serviço de extensão rural.

Figura 2 - Organograma do PBSM rural

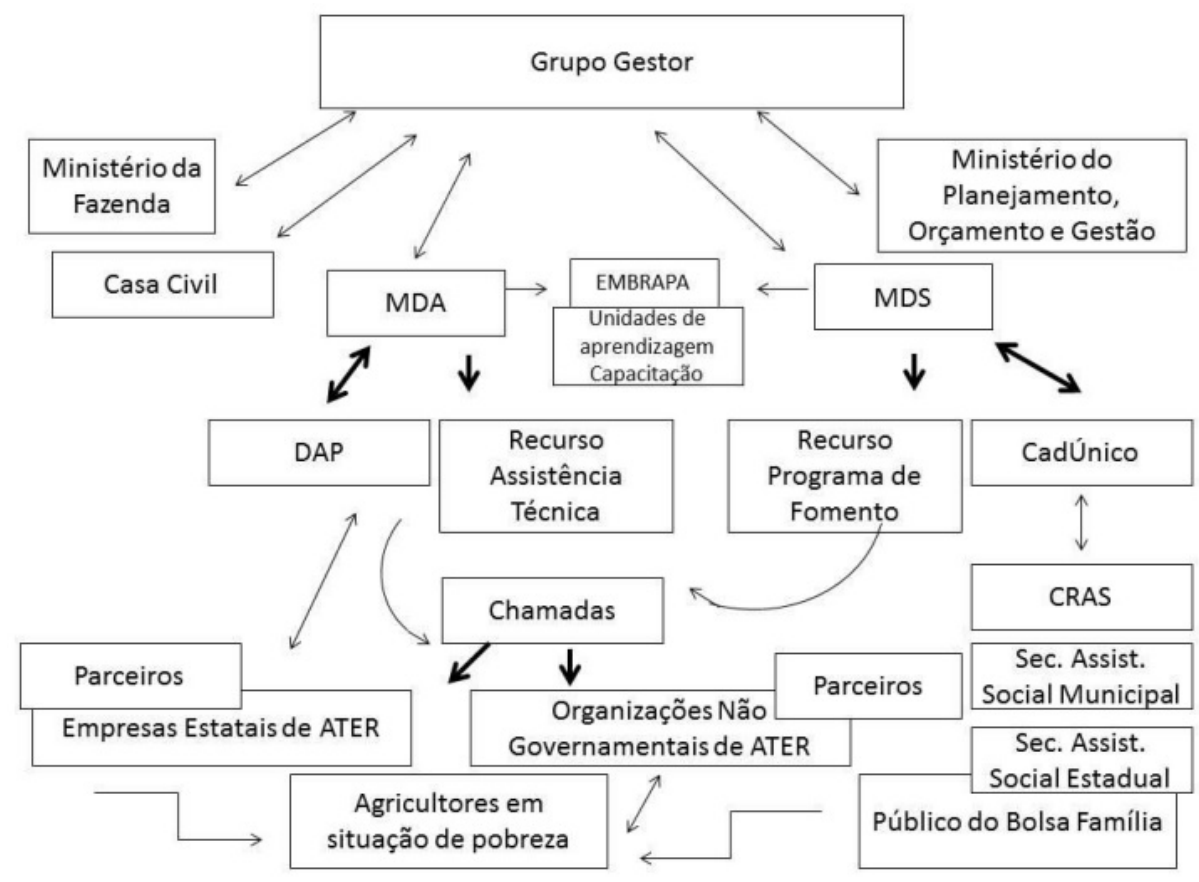

Fonte: Pacífico (2015)

Este organograma ilustra as articulações institucionais que foram necessárias para que o governo estruturasse fortemente a ideia de inclusão produtiva dos agricultores familiares, ante a contextualização da realidade do meio rural supracitada e como alternativa para melhorar a condição do público beneficiário, seja por meio do aumento da renda, seja pela qualidade de vida. Isso demonstra o quão importante foi construir uma narrativa forte que tivesse poder de convencimento para o conjunto desses atores.

Nesse contexto, o Programa Fomento foi um dos instrumentos que tratou sobre as ações de inclusão produtiva do PBSM rural com foco numa gestão compartilhada. O grupo gestor era então formado por representantes da Casa Civil; Ministério do Planejamento, Orçamento e Gestão; Ministério da Fazenda. E a sua operacionalização era realizada pelo Ministério do Desenvolvimento Social (MDS) e o pelo Ministério do Desenvolvimento Agrário (MDA), que foi 
extinto no ano de 2016, com algumas atribuições repassadas à Secretaria Especial de Agricultura Familiar e do Desenvolvimento Agrário (SEAD) junto à Casa Civil da Presidência da República e para o então criado Ministério do Desenvolvimento Social e Agrário (MDSA).

A função do MDS era disponibilizar os dados do sistema Cadúnico e o recurso a fundo perdido, no valor de $\mathrm{R} \$ 2.400,00$, para cada projeto de fomento via inclusão produtiva com a finalidade de aquisição de insumos e equipamentos. Já o MDA tinha a função de disponibilizar os dados da DAP e o recurso das chamadas públicas de assistência técnica para os serviços diferenciados de extensão rural. Quanto aos sistemas utilizados, o primeiro era referente às informações oriundas da assistência social sobre a população pobre, e o segundo era referente a quem é considerado agricultor familiar por meio das DAP emitidas, de forma que, nesta intercessão de ambos, os sistemas obtêm quem são os selecionados classificados como "agricultores familiares" e "pobres". Tal Programa também teve apoio da Empresa Brasileira de Pesquisa Agropecuária (Embrapa), por meio da doação de sementes e de ações de transferência de tecnologias para o início do processo produtivo.

A inserção da temática inclusão produtiva no meio rural do PBSM foi de fundamental importância para combater a pobreza perante os diferentes públicos situados na categoria da agricultura familiar, os quais, muitas das vezes, eram excluídos dos mercados e, principalmente, do acesso às políticas públicas. A argumentação do governo para manter essa ideia atrelou-se à relevância das atividades de inclusão produtiva ao tentar combater as causas da pobreza e transformar as ações em políticas de Estado (BRASIL, 2013b). Com efeito,

[...] a estratégia de inclusão produtiva rural inova ao combinar assistência técnica com recursos para investir na produção. Com dinheiro na mão e um projeto elaborado com o auxílio de técnicos especializados, as famílias melhoram sua produção e sua renda, viabilizando sua permanência no campo, de forma cada vez mais digna. (BRASIL, 2013c, p. 33).

Notou-se que o serviço de Assistência Técnica e Extensão Rural (ATER) tem papel estratégico para potencializar as ações de inclusão produtiva no meio rural, juntamente da política de fomento. O agente extensionista, junto à família beneficiária, realiza diagnóstico sobre as condições da unidade produtiva e, a partir desse panorama de informações, elabora um projeto de fomento para a organização produtiva. Este agente acompanha a implementação do projeto e assessora a família até o prazo de dois anos (BRASIL, 2013c).

Entende-se que a ATER e as ações de inclusão produtiva devam andar juntas, interligadas e intrínsecas para o melhor resultado na propriedade do agricultor familiar. A crítica, até então, era de que este público não tinha vocação agrícola e que somente com o acesso às políticas sociais, principalmente de transferência de renda, sairia da condição de pobreza (ALVES, 2001; NAVARRO; PEDROSO, 2014). O PBSM sai dessa lógica e propicia ao agricultor familiar interação com outras políticas públicas já implementadas, por diversos ministérios, para que também Ihes permita progredir economicamente, uma vez que, para "[...] se legitimar, o Estado precisa rapidamente tornar 'produtivos' aqueles agricultores que a sociedade julga e condena moralmente em face da sua ausência no moderno mundo do trabalho" (NIEDERLE, 2017, p. 172). Essa lógica vai ao encontro do que já ocorria com os territórios rurais e da cidadania.

No espaço rural, o PBSM ofereceu aos agricultores familiares o serviço de assistência técnica especializada e recursos de fomento, acesso à água e à energia elétrica, além de apoio à comercialização por meio de compras públicas e institucionais, principalmente do Programa de Aquisição de Alimentos (PAA) (BRASIL, 2013c). No Quadro 2, estão listadas as principais políticas 
do eixo inclusão produtiva no rural do PBSM, bem como o ministério responsável pela execução e o ano de lançamento. A ideia do governo amparou-se no fato de que não adiantava oferecer o serviço de ATER ou a liberação de recursos de fomento isolados, se não houvesse um ambiente propício que também garantisse outros direitos básicos, como saneamento, mobilidade urbana e igualdade no acesso à informação (BRASIL, 2012b).

Quadro 2 - Principais políticas do PBSM no eixo inclusão produtiva rural

\begin{tabular}{|c|c|c|}
\hline Política pública & Órgão executor (coordenador) & $\begin{array}{c}\text { Ano de } \\
\text { lançamento }\end{array}$ \\
\hline Luz para Todos & Ministério de Minas e Energia (MME) & 2003 \\
\hline $\begin{array}{c}\text { Programa de Aquisição de Alimentos } \\
\text { (PAA) }\end{array}$ & $\begin{array}{c}\text { Ministério do Desenvolvimento } \\
\text { Social (MDS)/Ministério do } \\
\text { Desenvolvimento Agrário (MDA) }\end{array}$ & 2003 \\
\hline $\begin{array}{c}\text { Política Nacional de Assistência Técnica e } \\
\text { Extensão Rural (PNATER) }\end{array}$ & MDA & 2004 \\
\hline $\begin{array}{c}\text { Programa Nacional de Alimentação } \\
\text { Escolar (PNAE) }\end{array}$ & Ministério da Educação (MEC) & 2009 \\
\hline $\begin{array}{c}\text { Chamadas públicas específicas de ATER } \\
\text { para os beneficiários do PBSM inseridos } \\
\text { nos Territórios da Cidadania }\end{array}$ & MDA & 2011 \\
\hline Bolsa Verde & Ministério do Meio Ambiente (MMA) & 2011 \\
\hline Água para Todos (cisternas) & MDS/MDA & 2011 \\
\hline Fomento de atividades produtivas & MEC/MDS & 2011 \\
\hline $\begin{array}{c}\text { Programa Nacional de Acesso ao Ensino } \\
\text { Técnico e Emprego (PRONATEC) - Eixo } \\
\text { Recursos Naturais }\end{array}$ & MI) & \\
\hline
\end{tabular}

Fonte: adaptado de Pacífico (2015) e Brasil (2015b).

Na visão do governo, a escolha dessas políticas públicas foi de fundamental importância para aperfeiçoar ainda mais as estratégias de inclusão produtiva no meio rural, pois uma só política não é suficiente para incluir os agricultores familiares no âmbito econômico e social (BRASIL, 2013c). Isoladamente, as políticas se tornam dispersas e tendem a não prosperar devido aos gargalos que o agricultor familiar sentirá em algum momento, seja na sua inserção em mercado, seja até mesmo na sociedade.

A Figura 3 ilustra a rota proposta pelo PBSM da inclusão produtiva rural trilhada pelos agricultores familiares empobrecidos, a qual é efetivada por meio do acesso a diferentes políticas públicas para melhorias da produção, segurança alimentar e renda familiar. "Essa rota tem como objetivo oferecer um conjunto de políticas públicas e que criam oportunidades e permitam às famílias caminharem, em direção à superação da pobreza e à melhoria da qualidade de vida de maneira sustentável" (BRASIL, 2015b, p. 3). 
Figura 3 - Rota da inclusão produtiva rural no PBSM

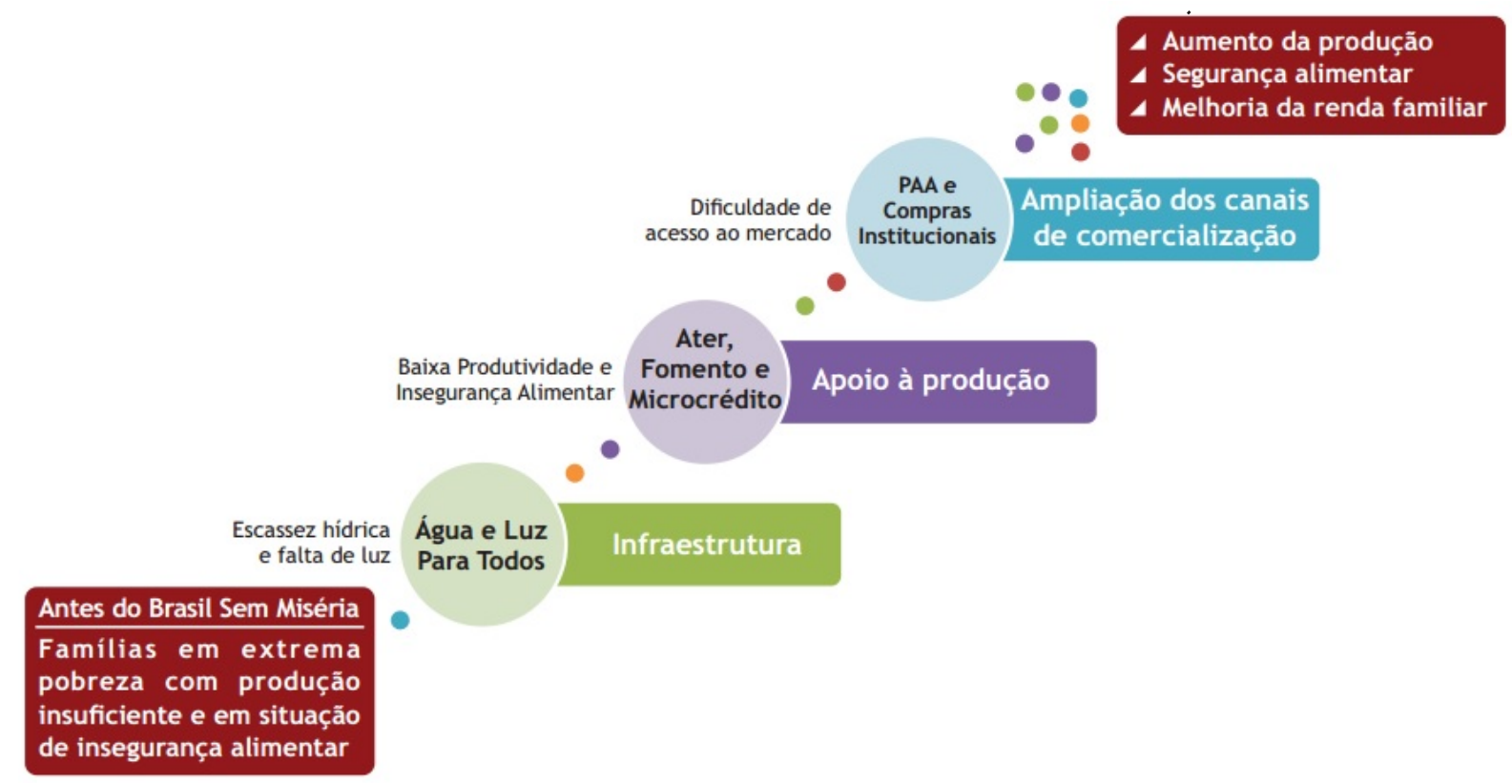

Fonte: Brasil (2015b).

A explicação para a estratégia de adotar esse pool de políticas públicas interligadas é que não se limitou apenas a colocar essas políticas sob um mesmo guarda-chuva, mas estas foram ampliadas e revigoradas desde sua gênese, além de articuladas e integradas sob a ótica da superação da extrema pobreza (BRASIL, 2013c).

O avanço da política de inclusão produtiva rural não está expresso em apenas uma política específica, ainda que não identificada, mas pela complementação de um conjunto de ações/ políticas inseridas dentro do Plano Brasil Sem Miséria. Numa busca exploratória entre as leis e os decretos que subsidiaram as políticas públicas inseridas no PBSM, apenas o PAA, a PNATER e o Programa de Fomento às Atividades Produtivas Rurais possuíam menção à "inclusão produtiva"10 explicitamente, no texto da referida legislação.

No PAA, verificou-se que a primeira finalidade do programa, descrita na Lei n. 10.696/2003, é a promoção da inclusão econômica e social do agricultor familiar, com fomento à produção, ao processamento e à industrialização de alimentos para, a posteriori, sua geração de renda (BRASIL, 2003).

Quanto à PNATER, a relação está mais imbricada, justificada pelo fato de a extensão rural ser forte apoiadora e promotora de atividades de intervenção social com foco na inclusão produtiva. Apesar de estar bem clara na descrição de quatro finalidades desta política, o termo "inclusão produtiva", propriamente dito, não se encontra no documento desta Lei. Os parágrafos que, de certa forma, trazem essa ideia estão exemplificados abaixo:

II- apoiar iniciativas econômicas que promovam as potencialidades e vocações regionais e locais;

III - aumentar a produção, a qualidade e a produtividade das atividades e serviços agropecuários e não agropecuários, inclusive agroextrativistas, florestais e artesanais;

\footnotetext{
${ }^{10}$ No estudo conduzido por Sousa (2019a) sobre políticas públicas de inclusão produtiva para agricultores familiares, as principais citadas pelos mediadores sociais foram: PRONAF, PNATER, PAA e PNAE.
} 
[...] V- assessorar as diversas fases das atividades econômicas, a gestão de negócios, sua organização, a produção, inserção no mercado e abastecimento, observando as peculiaridades das diferentes cadeias produtivas;

[...] X- promover o desenvolvimento e a apropriação de inovações tecnológicas e organizativas adequa, das ao público beneficiário e a integração deste ao mercado produtivo nacional. (BRASIL, 2010, p. 1).

Já no Programa de Fomento às Atividades Produtivas Rurais, verificou-se, no seu principal objetivo, que é organizar e estruturar as atividades produtivas dos agricultores familiares, com vistas à inclusão produtiva e à promoção da segurança alimentar e nutricional (BRASIL, 2011).

Portanto o que dizem as outras políticas públicas da agricultura familiar inseridas no PBSM sobre a inclusão produtiva não está explícito na legislação que remete a elas. O que se verifica é que o conjunto de políticas que compõem o PBSM tem finalidades implícitas que corroboram a inclusão produtiva. Ou melhor, tem competências únicas e diferenciadas que pode contribuir para potencializar as ações de inclusão produtiva na respectiva unidade de produção familiar e, por consequência, a superação da pobreza pelos agricultores familiares. Por sua vez, Niederle (2017) explica que, independentemente da tese da estratégia a ser buscada para os pobres rurais, o termo "inclusão produtiva" se tornou um mantra para as ações do Estado, bem como da sociedade civil organizada, no sentido de que esta expressão genérica assume significância distinta, em decorrência dos desacordos sobre o espaço de manobra política e as possíveis alternativas que existem para o público empobrecido do meio rural.

No entanto narrativas marginalizadas apontam, conforme assinaladas por Cazella e Búrigo (2011), que o PBSM não teria contemplado as particularidades da pobreza rural, pois não foram pensadas ações de microfinanças e tampouco medidas que favorecessem o acesso a terra, o que, por ora, reproduziria os mesmos problemas que ocorriam com o PRONAF. No mesmo sentido, Mello et al. (2015) criticaram os gargalos do Programa referentes ao pouco incremento nos investimentos de infraestrutura, baixo nível de expansão das famílias beneficiárias e dificuldades apresentadas na execução das ações interministeriais.

\section{CONSIDERAÇÕES FINAIS}

Com a narrativa pautada na extinção da extrema pobreza até o ano de 2014, que aqui explorou a discussão sobre a inclusão produtiva dos agricultores familiares, o governo verificou a necessidade de articular ações em três diferentes eixos estratégicos para abranger maior público beneficiário no PBSM. Assim, criou-se uma narrativa apresentando um problema central, no entorno da pobreza, que mobilizou boa parte da sociedade civil, as suas possíveis causas, as soluções necessárias para resolvê-lo e, em algumas situações, as consequências caso não fosse implantada tal política pública.

A narrativa evidenciou que o governo se sensibilizou ao empoderar a sociedade civil e inseri-la nas discussões, recebendo críticas e sugestões do PBSM para a efetivação da política e legitimação nas ações do governo, a fim de efetivar as transformações sociais propostas pela política.

A ideia problematizada foi que a privação que existia nas unidades familiares necessitaria de uma injeção de políticas públicas, além daquelas que transferem renda. Com o propósito de expandir a capacidade de autogestão e garantir a inclusão produtiva, desde que pautada por ações 
do Estado que readaptem de acordo com as características intrínsecas das múltiplas agriculturas familiares. Entretanto, em relação às políticas inseridas no PBSM, apenas três tinham em suas finalidades referência ao termo inclusão produtiva. Com isso, constatou-se que o conjunto de políticas do PBSM tinha finalidades implícitas que corroboravam a efetivação de ações de inclusão produtiva e, por consequência, a superação da pobreza pelos agricultores familiares.

Em tese, a ideia foi privilegiar os segmentos mais empobrecidos da agricultura familiar e suas organizações socioprodutivas para o acesso às políticas inseridas dentro do PBSM. A tentativa de superar a extrema pobreza requereu, desse modo, a ação intersetorial do Estado, uma vez que não existiu uma política específica de inclusão produtiva, mas o avanço de um conjunto de políticas complementares no âmbito do PBSM que tentou promover a dinâmica de inclusão socioeconômica dos beneficiários.

Com as alterações recentes no cenário político, contata-se a retomada do tema da pobreza e o arrefecimento do tema da inclusão produtiva na agenda política, embora, mais cedo ou mais tarde, essas temáticas precisarão ser retomadas em conjunto na narrativa governamental, assim como ocorreu no PBSM, para promover a redução da pobreza rural por meio de ações de inclusão produtiva junto aos diferentes agricultores familiares.

\section{REFERÊNCIAS}

ALVES, E. Agricultura familiar prioridade da Embrapa. Brasília: Embrapa, 2001.

ALVES, M. A.; BLIKSTEIN, I. Análise da narrativa. In: GODOI, C. K.; BANDEIRA-DEMELLO, R.; SILVA, A. B. (Org.). Pesquisa qualitativa em estudos organizacionais: paradigmas, estratégias e métodos. São Paulo: Saraiva, 2006.

BARDIN, L. Análise de conteúdo. São Paulo: Edições 70, 2011.

BLANDÓN, L. F. C. La narrativa de las políticas públicas en la jurisprudencia de la corte constitucional colombiana. Papel Político, Bogotá, v. 19, n. 2, p. 435-58, 2014.

BRASIL. Ministério do Desenvolvimento Social. Plano Brasil sem Miséria: Caderno de Resultados 2011/2014. Brasília-DF: MDS, 2015a.

BRASIL. Ministério do Desenvolvimento Social. Plano Brasil sem Miséria: Caderno de Resultados no meio rural. Brasília-DF: MDS, 2015b.

BRASIL. Ministério do Desenvolvimento Social e Combate à Fome. A inclusão produtiva rural no Brasil sem Miséria: o desafio da superação da pobreza no campo. Organizado por Janine Mello dos Santos. Brasília-DF: Ministério do Desenvolvimento Social e Combate à Fome; Secretaria de Avaliação e Gestão da Informação, 2015c. (Cadernos de Estudos Desenvolvimento Social em Debate, n. 23).

BRASIL. Ministério do Desenvolvimento Social. Diálogos Governo - Sociedade Civil: Brasil sem Miséria. Relatório da 3. ed. Brasília-DF: MDS, 2013a.

BRASIL. Ministério do Desenvolvimento Social. Diálogos Governo - Sociedade Civil: Brasil sem Miséria (Relatório da 4. ed). Brasília-DF: MDS, 2013b.

BRASIL. Ministério do Desenvolvimento Social. Dois anos de resultados do PBSM. Brasília-DF: MDS, 2013c.

BRASIL. Ministério do Desenvolvimento Social. Diálogos Governo - Sociedade Civil: Brasil Sem Miséria (Relatório da 2. Ed). Brasília-DF: MDS, 2012a. 
BRASIL. Ministério do Desenvolvimento Social. Um ano de resultados do PBSM. Brasília-DF: MDS, 2012b. BRASIL. Ministério do Desenvolvimento Social [MDS]. Devolutiva Diálogos Governo - Sociedade Civil: Brasil Sem Miséria. Brasília-DF: MDS, 2012c.

BRASIL. Ministério do Desenvolvimento Social [MDS]. Diálogos Brasil Sem Miséria Síntese (Relatório da 1. Ed). Brasília-DF: MDS, 2011 .

BRASIL. Decreto n. 7.644, de 16 de dezembro de 2011. Regulamenta o Programa de Fomento às Atividades Produtivas Rurais. Brasília-DF, 2011b.

BRASIL. Lei n. 12.188, de 11 de janeiro de 2010. Institui a Política Nacional de Assistência Técnica e Extensão Rural para a Agricultura Familiar e Reforma Agrária - PNATER. Brasília-DF, 2010.

BRASIL. Lei n. 10.696, de 25 de abril de 2002. Fica instituído o Programa de Aquisição de Alimentos, compreendendo as seguintes finalidades. Brasília-DF, 2003.

CAVALCANTI, J. S. B; WANDERLEY, M. N. B; NIEDERLE, P. A. Participação, território e cidadania: um olhar sobre a política de desenvolvimento territorial no Brasil. Recife: UFPE, 2014.

CAZELLA, A. A.; BÚRIGO, F. L. O plano Brasil sem Miséria não contempla as especificidades da pobreza rural. Observatório de Políticas Públicas para a Agricultura, Rio de Janeiro, v. 1, n. 38, p. 1-4, 2011.

FRANÇA, D. M. C. Políticas públicas de educação para a população do campo: uma análise do Pronacampo a partir da abordagem cognitiva. 2016. Tese (Doutorado em Educação) - Universidade Federal do Rio Grande do Sul, Porto Alegre, RS, 2016.

GRISA, C. Políticas públicas para a agricultura familiar no Brasil: produção e institucionalização das ideias. 2012. 280 f. Tese (Doutorado em Desenvolvimento, Agricultura e Sociedade) - Universidade Federal Rural do Rio de Janeiro, Rio de Janeiro, RJ, 2012.

GRISA, C.; SCHNEIDER, S. Três gerações de políticas públicas para a agricultura familiar e formas de interação entre sociedade e Estado no Brasil. Revista de Economia e Sociologia Rural, Brasília, v. 52, Supl. 1, p. 125-6, 2014.

INSTITUTO BRASILEIRO DE GEOGRAFIA E ESTATÍSTICA [IBGE]. Censo demográfico 2010. Rio de Janeiro: IBGE, 2011.

LÜDKE, M.; ANDRÉ, M. E. D. A. Pesquisa em educação: abordagens qualitativas. São Paulo: EPU, 1986.

LUKIC, M. R.; TOMAZINI, C. As ideias também importam: abordagem cognitiva e políticas públicas no Brasil. Curitiba: Juruá, 2013.

MATTEI, L. Pobreza e política de desenvolvimento territorial: noções, metodologias de mensuração e estratégias de enfrentamento do problema. In: MIRANDA, C.; TIBURCIO, B. (Org.). Políticas de desenvolvimento territorial e enfrentamento da pobreza rural no Brasil. Brasília: IICA, 2013.

MELLO, J; ANDRADE, B. T; MELCHIORI, C. E; OLIVEIRA, Y. R. A inclusão produtiva do Brasil sem miséria: estratégias e primeiros resultados. In: BRASIL. A inclusão produtiva rural no Brasil sem Miséria: o desafio da superação da pobreza no campo. Organizado por Janine Mello dos Santos. Brasília-DF: Ministério do Desenvolvimento Social e Combate à Fome; Secretaria de Avaliação e Gestão da Informação, 2015. (Cadernos de Estudos Desenvolvimento Social em Debate, n. 23). 
MINAYO, M. C. S. O desafio do conhecimento: pesquisa qualitativa em saúde. 14. ed. São Paulo: Editora Hucitec, 2015.

NAVARRO, Z.; PEDROSO, M. T. M. A agricultura familiar no Brasil: da promessa inicial aos impasses do presente. Revista de Economia do Nordeste, Fortaleza, v. 45, Suplemento especial, p. 6-17, 2014.

NIEDERLE, P. A. Afinal, que inclusão produtiva? A contribuição dos novos mercados alimentares. In: DELGADO, G. C.; BERGAMASCO, S. M. P. P. (Org). Agricultura familiar brasileira: desafios e perspectivas de futuro. Brasília: Ministério do Desenvolvimento Agrário, 2017.

PACíFICO, D. A. A territorialização da ação pública: análise da implementação do Plano Brasil Sem Miséria rural. In: CONGRESSO DA SOCIEDADE BRASILEIRA DE ECONOMIA, ADMINISTRAÇÃO E SOCIOLOGIA RURAL, 53., 26 jul. 2015, João Pessoa. Anais [...]. João Pessoa: UFPB, 2015.

RADAELLI, C. M. Logiques de pouvoirs et récits dans les politiques publiques de l'Union Européene. Revue française de science politique, Paris, v. 50, n. 2, p. 255-75, 2000.

RADAELLI, C. M. Récit (policy narrative). In: BOUSSAGUET, L.; JACQUOT, S.; RAVINET, P. Dictionnaire de politiques publiques. 2. ed. Paris: Presses de Sciences Po, 2006. p. 366-72.

ROE, E. M. Narrative policy analysis: theory and practice. Durham/London: Duke University Press, 1994.

SABATIER, P. A. Theories of the policy process. Boulder: Westview Press, 2007.

SERAFIM, M.; DIAS, R. B. Análise de política: uma revisão da literatura. Cadernos Gestão Social, Salvador, v. 3, n. 2, p. 121-34, 2012.

SERGIPE (Estado). Secretaria de Estado da Transparência e Controle. Bolsa Família mantém mais de 434,6 mil pessoas fora da extrema pobreza em SE. SETC, Aracaju, 30 nov. 2014. Disponível em: https:// bit.ly/3sBp8zV. Acesso em: 21 jun. 2018.

SOUSA, D. N. Mediadores sociais e políticas públicas de inclusão produtiva da agricultura familiar no Tocantins: (Des)conexões entre referenciais, ideias e práticas. 2019. Tese (Doutorado em Desenvolvimento Rural) - Universidade Federal do Rio Grande do Sul, Porto Alegre, RS, 2019a.

SOUSA, D. N. O que se entende por inclusão produtiva dos agricultores familiares? Um estudo de revisão bibliométrica. Cadernos de Ciência \& Tecnologia, Brasília, v. 36, n. 1, p. 1-13, 2019 b.

SOUSA, D. N.; NIEDERLE, P. A. A produção científica brasileira sobre o que se entende por inclusão produtiva: um recorte temporal entre 2005 e 2016. Revista Desenvolvimento Social, Montes Claros, v. 1, n. 23, p. 15-32, 2018.

SOUZA, C. Políticas públicas: uma revisão da literatura. Sociologias, Porto Alegre, v. 8, n. 16, p. 20-45, 2006.

\section{Sobre o autor:}

Diego Neves de Sousa: Doutor em Desenvolvimento Rural pela Universidade Federal do Rio Grande do Sul (UFRGS). Mestre em Extensão Rural pela Universidade Federal de Viçosa (UFV). Bacharel em Gestão de Cooperativas pela UFV. Sociólogo pela Universidade Paulista (UNIP). É analista da Embrapa Pesca e Aquicultura, no setor de transferência de tecnologia, atuando no desenvolvimento tecnológico e extensão inovadora. Atualmente, é editor das publicações da Embrapa Pesca e Aquicultura e coordenador do projeto Componente em 
Transferência de Tecnologia do BRS Aqua - Ações Estruturantes e Inovação para o Fortalecimento das Cadeias Produtivas da Aquicultura no Brasil (BNDES/EMBRAPA/MAPA/CNPq). E-mail: diego.sousa@embrapa.br, Orcid: http://orcid.org/0000-0003-3124-5150 
